\title{
A Multimodel Assessment of Future Projections of North Atlantic and European Extratropical Cyclones in the CMIP5 Climate Models*
}

\author{
GIUSEPPE ZAPPA AND LEN C. SHAFFREY \\ National Centre for Atmospheric Science, Department of Meteorology, University of Reading, \\ Reading, United Kingdom \\ KEVIN I. HODGES \\ National Centre for Earth Observation, University of Reading, Reading, United Kingdom \\ Phil G. SANSOM AND DAVID B. STEPHENSON \\ Exeter Climate Systems, University of Exeter, Exeter, United Kingdom
}

(Manuscript received 30 July 2012, in final form 22 January 2013)

\begin{abstract}
The response of North Atlantic and European extratropical cyclones to climate change is investigated in the climate models participating in phase 5 of the Coupled Model Intercomparison Project (CMIP5). In contrast to previous multimodel studies, a feature-tracking algorithm is here applied to separately quantify the responses in the number, the wind intensity, and the precipitation intensity of extratropical cyclones. Moreover, a statistical framework is employed to formally assess the uncertainties in the multimodel projections. Under the midrange representative concentration pathway (RCP4.5) emission scenario, the December-February (DJF) response is characterized by a tripolar pattern over Europe, with an increase in the number of cyclones in central Europe and a decreased number in the Norwegian and Mediterranean Seas. The June-August (JJA) response is characterized by a reduction in the number of North Atlantic cyclones along the southern flank of the storm track. The total number of cyclones decreases in both DJF $(-4 \%)$ and JJA $(-2 \%)$. Classifying cyclones according to their intensity indicates a slight basinwide reduction in the number of cyclones associated with strong winds, but an increase in those associated with strong precipitation. However, in DJF, a slight increase in the number and intensity of cyclones associated with strong wind speeds is found over the United Kingdom and central Europe. The results are confirmed under the high-emission RCP8.5 scenario, where the signals tend to be larger. The sources of uncertainty in these projections are discussed.
\end{abstract}

\section{Introduction}

Extratropical cyclones can have a large socioeconomic impact. High winds and extreme precipitation from extratropical cyclones can result in windstorm damage, flooding, and coastal storm surge (Lamb 1991; Fink et al. 2009; Della-Marta and Pinto 2009). Extratropical cyclones

\footnotetext{
* Supplemental information related to this paper is available at the Journals Online website: http://dx.doi.org/10.1175/JCLI-D12-00573.s1.

Corresponding author address: Giuseppe Zappa, National Centre for Atmospheric Science, Department of Meteorology, University of Reading, Earley Gate, Reading RG6 6BB, United Kingdom.

E-mail: g.zappa@reading.ac.uk
}

are also an important component of the midlatitude water cycle (Hawcroft et al. 2012), providing freshwater for agriculture and society. Developing our knowledge of how extratropical cyclones might change in a warmer world is critical to understanding how societies may need to adapt to climate change.

The Fourth Assessment Report (AR4) of the Intergovernmental Panel on Climate Change (IPCC) summarized that increasing greenhouse gases will lead to "a poleward shift of storm tracks in both hemispheres that is particularly evident in the SH [Southern Hemisphere], with greater storm activity at higher latitudes" (Meehl et al. 2007). There is evidence that this simple picture is not a good description of the response of the North Atlantic storm track. In winter, climate model simulations show an eastward extension of the storm track associated 
with an increased storminess over the United Kingdom and central Europe (Sinclair and Watterson 1999; Geng and Sugi 2003; Leckebusch and Ulbrich 2004; Pinto et al. 2007b; Bengtsson et al. 2006; Pinto et al. 2009; Catto et al. 2011). This could enhance the windstorm risk and the economic loss potential caused by cyclone activity (Pinto et al. 2007a; Della-Marta and Pinto 2009). Climate models also show a future reduction in the number of Mediterranean cyclones (Bengtsson et al. 2006; Lionello and Giorgi 2007; Raible et al. 2010), which could increase the susceptibility of the region to droughts. However, the spread in the model responses appears to be large (Ulbrich et al. 2008, 2009; Harvey et al. 2012).

A source of uncertainty in the response of North Atlantic cyclones is given by the complex interaction between different physical drivers of change (Woollings 2010). Because extratropical cyclones grow as baroclinic instabilities organized along oceanic storm tracks (Hoskins and Valdes 1990), any change in the mean baroclinicity of the atmosphere or in the efficiency of baroclinic conversion will likely affect cyclone behavior (O'Gorman 2010). The future increase in the atmospheric moisture content is a major driver of changes (Schneider et al. 2010). Increased latent heat release in the warm sector of cyclones might enhance cyclone development by generating additional available potential energy (Laîné et al. 2009). However, the increased poleward and upward moisture fluxes will also tend to reduce the zonal-mean baroclinicity so that cyclone development might be instead inhibited (Held 1993). The polar amplification of global warming (Hwang et al. 2011), the expansion of the tropics (Fu et al. 2006), and the weakening of the meridional overturning circulation (MOC) will further affect the baroclinicity of the North Atlantic region (Woollings et al. 2012).

As extratropical cyclones are complex dynamical features, their diverse behavior is best analyzed by tracking the individual trajectories using objective featuretracking algorithms. This allows the response to climate change in the number and the intensities of cyclones to be quantified separately. However, because of the lack of high-frequency data, cyclone tracking could not be applied to analyze earlier multimodel dataset, such as those provided in phase 3 of the Coupled Model Intercomparison Project (CMIP3). Emerging pictures in the storm-track response to climate change, such as the one given in the AR4, have been built on the existence of consistent responses in single-model studies based on tracking algorithms (Schubert et al. 1998; Geng and Sugi 2003; Leckebusch and Ulbrich 2004; Bengtsson et al. 2006; Pinto et al. 2009; Catto et al. 2011) and on the results of multimodel analyses based on simple measures of storm-track activity. This includes Eulerian bandpass filter variance statistics (Yin 2005; Ulbrich et al. 2008; O'Gorman 2010) and simple cyclone identification techniques (Lambert and Fyfe 2006). These approaches have limitations. The insight from the comparison of single-model studies is limited by the use of different tracking algorithms and metrics of cyclone intensity, which might highlight different aspects of cyclone behavior in the different models (Neu et al. 2013). The Eulerian measures of storm-track activity cannot discriminate between the changes in the number and intensity of cyclones, and provide no direct information on the response of the extremes of cyclone intensity.

The aim of this study is to assess the projections of North Atlantic and European cyclones by investigating the climate change response of the models from phase 5 of the Coupled Model Intercomparison Project (CMIP5; Taylor et al. 2012). As high-frequency data (6 hourly) are included for the first time in CMIP5, a cyclone-tracking algorithm (Hodges 1994, 1995, 1999) can be used to quantify the future changes in the number, the wind speed (dynamical intensity), and the precipitation rate (hydrological intensity) of cyclones in a wide range of models. Moreover, a statistical framework is adopted to quantify the uncertainties in the model responses (Sansom et al. 2013). Both the boreal winter [December-February (DJF)] and summer [June-August (JJA)], which have been previously given little attention, are investigated.

The structure of the paper is as follows. The dataset, the tracking algorithm, and the statistical framework are described in section 2 . The future changes in the mean storminess are presented in section 3. Section 4 examines the future changes in the cyclones of strong intensity. Section 5 discusses the relation with the large-scale state of the atmosphere and ocean. The conclusions of the study are presented in section 6 .

\section{Data and methods}

\section{a. CMIP5 models}

The climate change response of 19 CMIP5 models is determined by comparing 30-yr periods of the historical (1976-2005) present-day simulations and the future climate simulations (2070-99) forced by the representative concentration pathway 4.5 (RCP4.5) and 8.5 (RCP8.5) scenarios (Taylor et al. 2012). In the historical (HIST) simulations, the CMIP5 models are forced by the observed greenhouse gas (GHG) concentrations, ozone, solar forcing, land use, and aerosols over the last 150 years. The RCP4.5 simulations are future scenarios conditional on a midrange mitigation of GHG emissions. In particular, $\mathrm{CO}_{2}$ emissions peak by 2040 and progressively decline so that $\mathrm{CO}_{2}$ concentrations are stabilized at 543 ppm by 2100 . 
This roughly corresponds to a doubling of $\mathrm{CO}_{2}$ concentrations with respect to preindustrial conditions. High GHG emissions are instead specified in the RCP8.5 scenario, where $\mathrm{CO}_{2}$ concentrations do not stabilize within the twenty-first century (Meinshausen et al. 2011).

The 19 CMIP5 models considered in this study are listed in Table 1, including their full expanded names, horizontal and vertical resolutions, and the number of analyzed runs of the HIST and RCP ensemble simulations.

\section{b. Cyclone tracking and data}

Cyclones are identified and tracked using the Hodges $(1994,1995,1999)$ objective feature-tracking algorithm. This algorithm has already been applied to study the future response of extratropical cyclones in single-model studies (Bengtsson et al. 2006, 2009; Catto et al. 2011). The main characteristics of the tracking algorithm are as follows. The 850 -hPa vorticity is computed from the 6-hourly zonal and meridional wind speeds and it is then smoothed on a T42 grid by removing the spectral components of total wavenumbers larger than 42 and smaller than 6 . This procedure filters the small-scale noise and the largescale background field. Cyclones are then identified as relative maxima in the filtered vorticity that exceed an intensity of $10^{-5} \mathrm{~s}^{-1}$. The T42 smoothing also allows cyclones of similar spatial scales to be identified in models of different atmospheric resolutions (Blender and Schubert 2000). Once the vorticity maxima are identified, their tracks are determined by minimizing a cost function for the track smoothness, measured as changes in direction and speed, subject to constraint on displacement and track smoothness. Finally, to avoid the inclusion of unrealistic stationary and short-lived features, only the cyclone tracks that have a lifetime greater than 2 days and propagation greater than $1000 \mathrm{~km}$ are retained for the analysis. The future responses appear to be only weakly sensitive to halving this threshold.

Measures of both the dynamical and of the hydrological intensity of cyclones are evaluated. The dynamical intensity of cyclones is measured by referencing the tracks to the full-resolution maximum wind speed at $850 \mathrm{hPa}$ searched within a $6^{\circ}$ spherical cap centered on the T42 vorticity maxima. The cyclone hydrological intensity is measured as the 6-hourly precipitation rate averaged over a $5^{\circ}$ spherical cap. The 6-hourly precipitation rate, which is not a standard CMIP5 diagnostic, is obtained by averaging the 3-hourly precipitation rate at the times leading and following the one of vorticity estimation. The choice of these metrics is also motivated from an impact assessment perspective, as winds and precipitation are strongly related to windstorms and floods. The sensitivity of the results to other measures of dynamical intensityminimum-mean sea level pressure (MSLP) and maximum
T42 vorticity at $850 \mathrm{hPa}$-has been tested and is briefly discussed in section $4 \mathrm{a}$. The spatial maps of the number of cyclones per month per unit area (i.e., the track density) and of the mean precipitation and wind speeds associated with cyclones are computed using the spherical kernel estimators described in Hodges (1996). Because of limited data availability, the precipitation associated with cyclones in the RCP scenarios is only evaluated for the 18-yr period 2082-99, which is the standard end-of-thecentury CMIP5 output period for 3-hourly precipitation.

\section{c. Statistical framework}

In this study, the mean climate response $\beta$ is estimated from the unweighted multimodel-mean difference between the historical and future day simulations. If available, multiple runs from each model are first averaged for each scenario. Sansom et al. (2013) showed that $\beta$ is equivalent to the maximum likelihood (ML) estimate of the expected climate response from a two-way analysis of variance (ANOVA) framework (see the appendix). We use this statistical framework to evaluate the statistical significance of the mean climate response and to compare the size of the mean climate response with internal variability (signal-to-noise ratio). Internal variability is here defined as the sampling uncertainty in the 30-yr means that is induced by different initial conditions.

Consensus in multimodel projections is often evaluated by the sign agreement in the climate responses, or by comparing the size of the mean climate response with the spread of the model responses. These approaches tend to systematically reject consensus where the mean climate response is small relative to the internal variability (i.e., in regions of low signal-to-noise ratio). However, additional information can be gained from a statistical analysis in regions of small mean climate response if climate models agree that the response is small.

To quantify this, we use the ANOVA framework to determine the uncertainty in the mean climate response from the differences in the responses of the models, which is called the structural uncertainty in Sansom et al. (2013), and from the internal variability. If the variance ratio $f^{2}$ of the structural uncertainty to the internal variability is small $\left(f^{2}<1\right)$, there is consensus between the model responses, regardless of the absolute size of the mean response. As the responses of the cyclone tracks generally have a low signal-to-noise ratio (see section 3), the choice of this metric seems to be appropriate for this study. The $90 \%$ confidence intervals on the mean climate response caused by internal variability are presented for key quantities. The confidence intervals here are estimates of the spread in the mean climate response one would obtain if CMIP5 runs were repeated (i.e., perturbed the initial conditions). In other 
TABLE 1. List of CMIP5 models considered in the study. For each model the following features are described: the model expansion (acronym), the model-developing institution, the resolution of the atmospheric component, the number of historical (i.e., HIST) and RCP4.5/RCP8.5 runs, and the availability of high-frequency precipitation (Precip.) data. The dimensions of the output Gaussian grids are also indicated in brackets for the spectral models. It should be noted that precipitation is available for only one CNRM-CM5 HIST run and MIROC5 includes only two ensembles in the RCP8.5 run.

\begin{tabular}{|c|c|c|c|c|c|c|c|}
\hline & \multicolumn{2}{|c|}{ Basic model information } & \multicolumn{2}{|c|}{ Atmospheric resolution } & \multicolumn{2}{|c|}{ No. of runs } & \multirow{2}{*}{$\begin{array}{l}\text { Precip. } \\
\text { Y/N }\end{array}$} \\
\hline & Model name & Institution & Horizontal & Vertical & HIST & $\mathrm{RCP}$ & \\
\hline 1 & $\begin{array}{l}\text { BCC Climate System Model, } \\
\text { version } 1.1 \text { (BCC-CSM1.1) }\end{array}$ & $\begin{array}{l}\text { Beijing Climate Center (BCC), } \\
\text { China }\end{array}$ & $\mathrm{T} 42(128 \times 64)$ & 26 & 3 & 1 & $\mathrm{Y}$ \\
\hline 2 & $\begin{array}{l}\text { Second Generation Canadian } \\
\text { Earth System Model } \\
\text { (CanESM2) }\end{array}$ & $\begin{array}{l}\text { Canadian Centre for Climate } \\
\text { Modelling and Analysis } \\
\text { (CCCma), Canada }\end{array}$ & T63 $(128 \times 64)$ & 35 & 5 & 1 & $\mathrm{~N}$ \\
\hline 3 & $\begin{array}{l}\text { CNRM Coupled Global } \\
\text { Climate Model, } \\
\text { version } 5 \text { (CNRM-CM5) }\end{array}$ & $\begin{array}{l}\text { Centre National de } \\
\text { Recherches Météorologiques } \\
\text { (CNRM), France }\end{array}$ & TL127 $(256$ × 128) & 31 & 5 & 1 & $\mathrm{Y}$ \\
\hline 4 & $\begin{array}{l}\text { CSIRO Mark, version } \\
\text { 3.6.0 (CSIRO Mk3.6.0) }\end{array}$ & $\begin{array}{l}\text { Commonwealth Scientific and } \\
\text { Industrial Research Organisation } \\
\text { (CSIRO), Australia }\end{array}$ & T63 $(192 \times 96)$ & 18 & 4 & 5 & $\mathrm{~N}$ \\
\hline 5 & $\begin{array}{l}\text { EC-Earth Consortium } \\
\text { (EC-EARTH) }\end{array}$ & European Consortium (EC) & TL159 $(320 \times 160)$ & 62 & 3 & 3 & $\mathrm{Y}$ \\
\hline 6 & $\begin{array}{l}\text { Flexible Global Ocean- } \\
\text { Atmosphere-Land System } \\
\text { Model gridpoint, second } \\
\text { spectral version (FGOALS-g2) }\end{array}$ & $\begin{array}{l}\text { State Key Laboratory of Numerical } \\
\text { Modeling for Atmospheric } \\
\text { Sciences and Geophysical Fluid } \\
\text { Dynamics (LASG), China }\end{array}$ & $128 \times 60$ & 26 & 1 & 1 & $\mathrm{Y}$ \\
\hline 7 & $\begin{array}{l}\text { GFDL Earth System Model with } \\
\text { MOM4 ocean component } \\
\text { (GFDL-ESM2M) }\end{array}$ & $\begin{array}{l}\text { Geophysical Fluid Dynamics } \\
\text { Laboratory (GFDL), United States }\end{array}$ & $144 \times 90$ & 24 & 1 & 1 & $\mathrm{Y}$ \\
\hline 8 & $\begin{array}{l}\text { GFDL Earth System Model with } \\
\text { GOLD ocean component } \\
\text { (GFDL-ESM2G) }\end{array}$ & GFDL, United States & $144 \times 90$ & 24 & 1 & 1 & $\mathrm{Y}$ \\
\hline 9 & $\begin{array}{l}\text { Hadley Centre Global } \\
\text { Environment Model, version } 2 \\
\text { (Earth System) (HadGEM2-ES) }\end{array}$ & $\begin{array}{l}\text { Met Office Hadley Centre, } \\
\text { United Kingdom }\end{array}$ & $192 \times 144$ & 38 & 1 & 1 & $\mathrm{~N}$ \\
\hline 10 & $\begin{array}{l}\text { Hadley Centre Global } \\
\text { Environment Model, version } 2 \\
\text { (Carbon Cycle) (HadGEM2-CC) }\end{array}$ & $\begin{array}{l}\text { Met Office Hadley Centre, } \\
\text { United Kingdom }\end{array}$ & $192 \times 144$ & 38 & 2 & 1 & $\mathrm{~N}$ \\
\hline 11 & $\begin{array}{l}\text { INM Coupled Model, version } 4.0 \\
\text { (INM-CM4) }\end{array}$ & $\begin{array}{l}\text { Institute of Numerical } \\
\text { Mathematics (INM), Russia }\end{array}$ & $180 \times 120$ & 21 & 1 & 1 & $\mathrm{Y}$ \\
\hline 12 & $\begin{array}{l}\text { IPSL Coupled Model, version 5, } \\
\text { coupled with NEMO, low } \\
\text { resolution (IPSL-CM5A-LR) }\end{array}$ & $\begin{array}{l}\text { L'Institut Pierre-Simon Laplace } \\
\text { (IPSL), France }\end{array}$ & $96 \times 96$ & 39 & 4 & 4 & $\mathrm{Y}$ \\
\hline 13 & $\begin{array}{l}\text { IPSL Coupled Model, version 5, } \\
\text { coupled with NEMO, medium } \\
\text { resolution (IPSL-CM5A-MR) }\end{array}$ & IPSL, France & $144 \times 143$ & 39 & 1 & 1 & $\mathrm{Y}$ \\
\hline 14 & $\begin{array}{l}\text { MPI Earth System Model, low } \\
\text { resolution (MPI-ESM-LR) }\end{array}$ & $\begin{array}{l}\text { Max Planck Institute (MPI) for } \\
\text { Meteorology, Germany }\end{array}$ & T63 $(192 \times 96)$ & 47 & 3 & 3 & $\mathrm{~N}$ \\
\hline 15 & $\begin{array}{l}\text { MRI Coupled Atmosphere-Ocean } \\
\text { General Circulation Model, } \\
\text { version } 3 \text { (MRI-CGCM3) }\end{array}$ & $\begin{array}{l}\text { Meteorological Research Institute } \\
\text { (MRI), Japan }\end{array}$ & TL159 $(320 \times 160)$ & 48 & 5 & 1 & $\mathrm{~N}$ \\
\hline 16 & MIROC, version 5 (MIROC5) & $\begin{array}{l}\text { Model for Interdisciplinary Research } \\
\text { on Climate (MIROC), Japan }\end{array}$ & $\mathrm{T} 85(256 \times 128)$ & 56 & 5 & 3 & $\mathrm{Y}$ \\
\hline 17 & $\begin{array}{l}\text { MIROC, Earth System Model } \\
\text { (MIROC-ESM) }\end{array}$ & MIROC, Japan & $\mathrm{T} 42(128 \times 64)$ & 80 & 3 & 1 & $\mathrm{Y}$ \\
\hline 18 & $\begin{array}{l}\text { MIROC, Earth System Model, } \\
\text { Chemistry Coupled } \\
\text { (MIROC-ESM-CHEM) }\end{array}$ & MIROC, Japan & T42 $(128 \times 64)$ & 80 & 1 & 1 & $\mathrm{Y}$ \\
\hline 19 & $\begin{array}{l}\text { Norwegian Earth System Model, } \\
\text { version } 1 \text { (intermediate } \\
\text { resolution) (NorESM1-M) }\end{array}$ & $\begin{array}{l}\text { Norwegian Climate Center (NCC), } \\
\text { Norway }\end{array}$ & $144 \times 96$ & 26 & 3 & 1 & $\mathrm{Y}$ \\
\hline
\end{tabular}




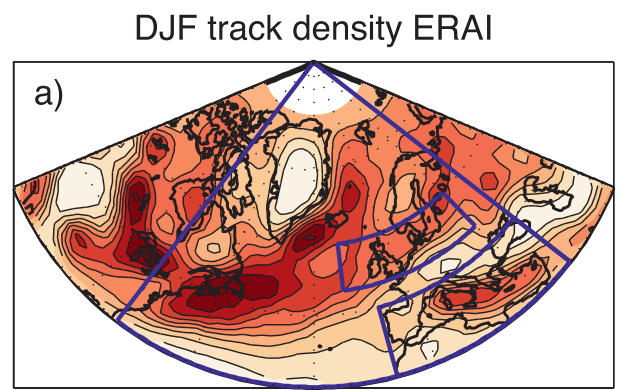

DJF CMIP5 bias

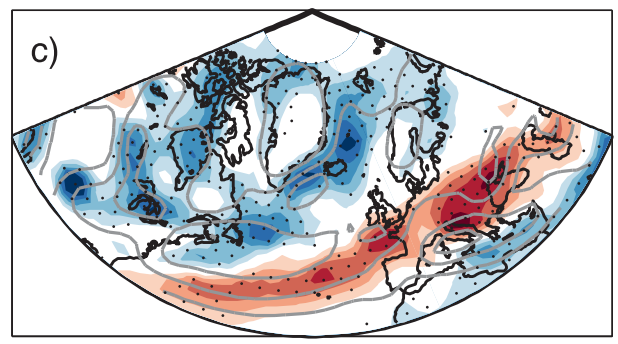

JJA track density ERAI

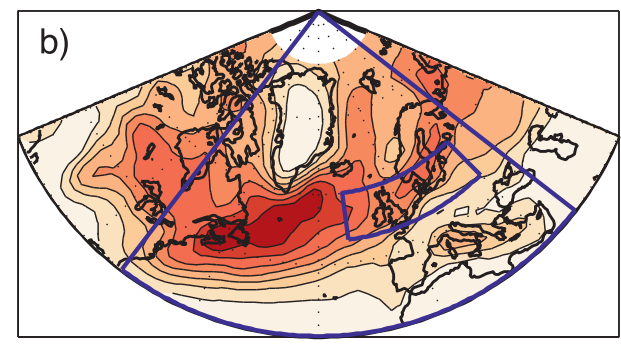

JJA CMIP5 bias
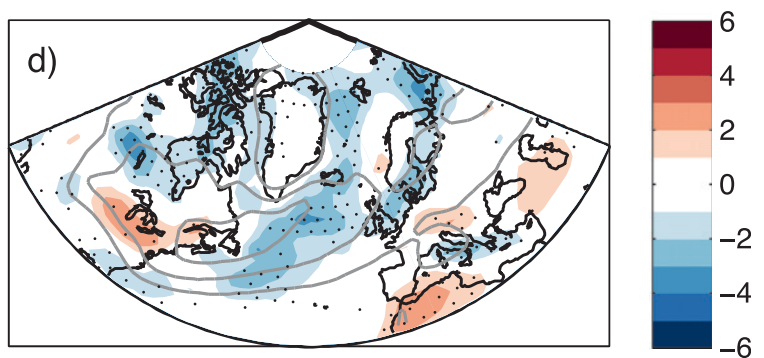

FIG. 1. (a),(b) Track density in ERA-Interim (1980-2009) and (c),(d) mean track density bias of CMIP5 models in the HIST simulations relative to ERA-Interim, for (left) DJF and (right) JJA. Units are in number of cyclones per month per unit area, where unit area is equivalent to a $5^{\circ}$ spherical cap. In (a),(b), the large blue circular sector defines the region of the North Atlantic and European cyclones. The small boxes define the Mediterranean [in (a) only] and central European area of interests. In (c),(d), stippling shows where more than $80 \%$ of the models have a bias of the same sign, and the contours show the CMIP5-averaged track density with isolines every four cyclones per month per unit area.

words, they capture the uncertainty caused by internal variability in the runs but not the uncertainty caused by differences in the responses of the models.

\section{Future response of the mean storminess}

In this section, we discuss the projected response of North Atlantic and European extratropical cyclones to climate change in CMIP5. We begin by recapping the results of Zappa et al. (2013), who investigated the biases of the CMIP5 historical simulations against observations. The DJF and JJA mean climate change responses in the CMIP5 models (RCP4.5 minus HIST) are then presented for the track density and intensity of North Atlantic cyclones. The individual model track density responses can be found in the supplemental material (available online at http://dx.doi.org/10.1175/JCLI-D-12-00573.s1). Finally, the sensitivity of the climate change response in the $\mathrm{RCP} 8.5$ scenario is discussed.

\section{a. The ability of the CMIP5 models to represent North Atlantic and European cyclones}

Figures 1a and 1c show the DJF track density from the European Centre for Medium-Range Weather Forecasts (ECMWF) Interim Re-Analysis (ERA-Interim; 1980-2009) and the mean bias of the CMIP5 models
(HIST minus ERA-Interim). The CMIP5 models tend to underestimate track density in the Norwegian Sea and to overestimate it in a zonal band between the subtropical Atlantic and central Europe. The magnitude of the biases are on the order of $10 \%-30 \%$ of ERA-Interim values, and they show that the simulated North Atlantic storm track is on average southward displaced in the Atlantic and too zonal into Europe. In the Mediterranean area, too many cyclones tend to propagate to the northeast relative to the Alps, and a too few propagate to the southeast along the Mediterranean Sea. However, the CMIP5 models differ in the extent that they can capture the observed spatial distribution of cyclones. In particular, Zappa et al. (2013) show that some models tend to have a realistic tilt of the North Atlantic storm track and small biases in cyclone intensity, so that the sensitivity of the future responses to the historical biases can be tested.

Figure $1 \mathrm{~d}$ shows that the JJA track density bias of the CMIP5 models (HIST minus ERA-Interim) is smaller than that found in DJF. As discussed in Zappa et al. (2013), the CMIP5 models are better at capturing the location and the tilt of the North Atlantic storm track in JJA. However, some models tend to underestimate the total number of cyclones, which is associated with the mean track density bias found in Fig. 1d. The Mediterranean 
track density

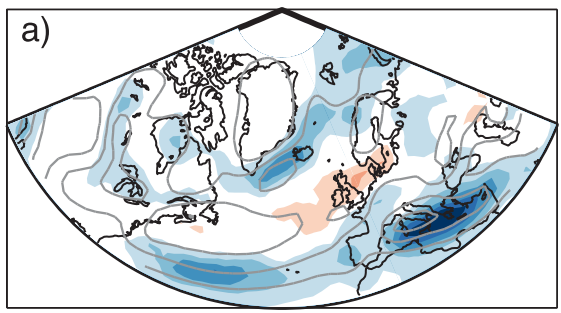

wind intensity

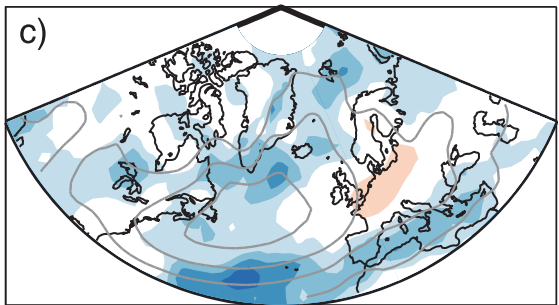

precip intensity

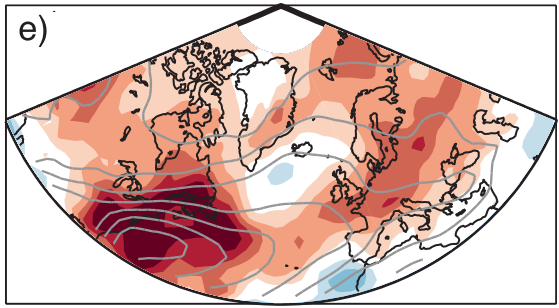

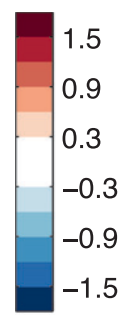

$-1.5$
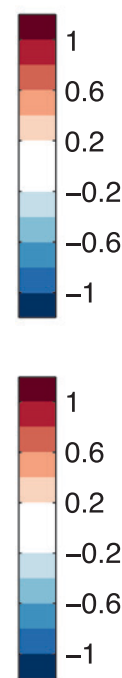

track density

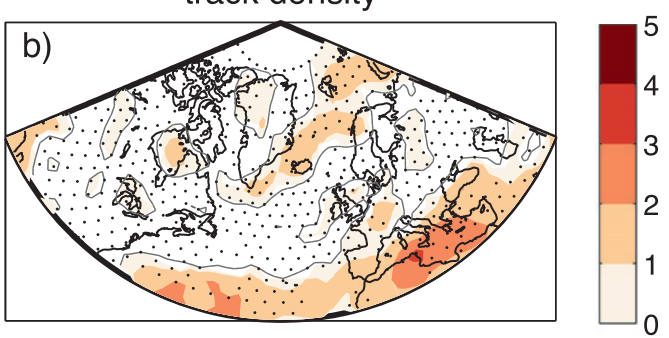

wind intensity

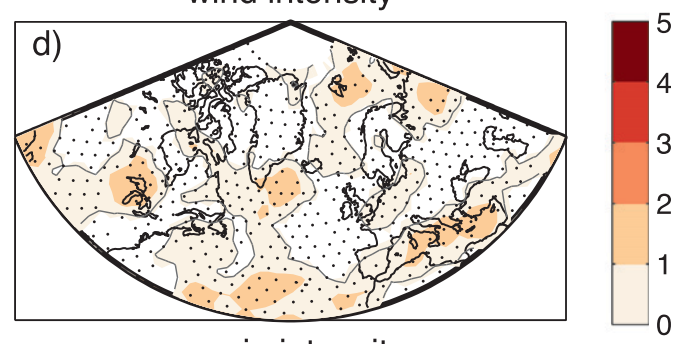

precip intensity

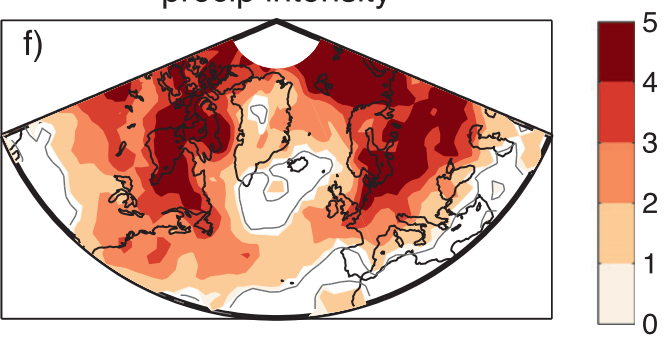

FIG. 2. (left) Mean DJF multimodel response and (right) statistical analysis of the (a),(b) track density, (c),(d) mean cyclone dynamical intensity measured by $850-\mathrm{hPa}$ wind speed, and (e),(f) mean precipitation intensity. In the left panels, the gray contours show the multimodel-mean values in the HIST simulations with contour intervals (CIs) of four cyclones per month per unit area, $4 \mathrm{~m} \mathrm{~s}^{-1}$, and $2 \mathrm{~mm} \mathrm{day}^{-1}$ for (a),(c), and (e), respectively. The right panels show the signal-to-noise ratio $\beta / \sigma$ in the regions where the mean climate response is statistically significant at the $5 \%$ level. In (b),(d), the stippling is applied where $f^{2}<1$ to show regions of consensus on the size of the responses.

storm track shows weaker activity in JJA than in DJF in both the ERA-Interim and the CMIP5 models.

\section{b. Winter track density response}

We now describe the mean DJF CMIP5 track density response to climate change for the RCP4.5 scenario. Figure 2a shows the mean climate response (shading) and the mean state in the HIST simulations (contours). Moreover, Fig. 2b shows the statistical analysis based on the Sansom et al. (2013) statistical framework. The shading identifies the regions where the mean climate response is statistically different from zero at the $5 \%$ level. The color of the shading gives the signal-to-noise ratio $\beta / \sigma$. Black stippling identifies areas with consensus on the responses of the models $\left(f^{2}<1\right)$.

The response in DJF track density over Europe is dominated by a tripolar pattern. There is a reduction in track density in the Norwegian and Mediterranean Seas and subtropical central Atlantic, while the track density increases close to the British Isles. The overall track density response over the North Atlantic suggests a reduction in the tilt of the North Atlantic storm track, and of an eastward extension of the storm track into Europe. This is consistent with the increase in the eastern Atlantic storm-track activity found by Ulbrich et al. (2008) in the CMIP3 models and by Harvey et al. (2012) in CMIP5. The mean track density response also resembles what found in some previous single-model studies (Sinclair and Watterson 1999; Geng and Sugi 2003; Leckebusch and Ulbrich 2004; Pinto et al. 2007b; Bengtsson et al. 2006; Pinto et al. 2009; Catto et al. 2011).

The analysis based on the statistical framework of Sansom et al. (2013) shows that the above-described responses are all statistically significant at the 5\% level (Fig. 2b). The signal-to-noise ratio is typically on the order of one, with larger values being found in the Mediterranean and smaller values over the British Isles. Consensus in the responses of CMIP5 models is found over most of the domain. This includes regions of low signal-to-noise ratio, which suggests that CMIP5 models agree that little 

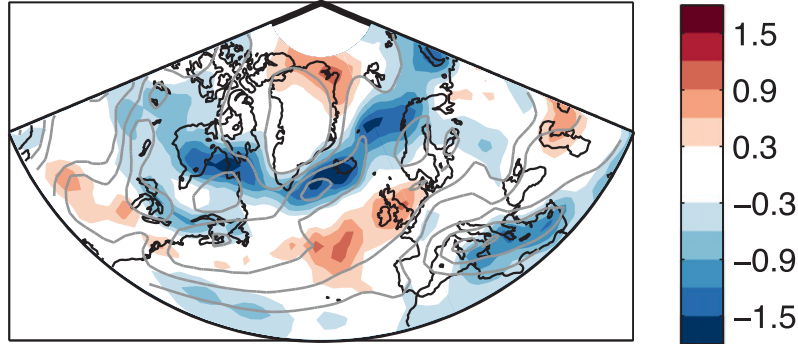

FIG. 3. Mean DJF track-density response (RCP4.5 minus HIST) computed for the four models with the best representation of the location and tilt of the North Atlantic storm track in CMIP5. Units are in number of cyclones per month per unit area. Gray contours show the mean historical track density with isolines every four cyclones per month per unit area.

track density change will occur in the western Atlantic and North America.

As described above, the most prominent spatial DJF biases in the CMIP5 models is a tendency to poorly capture the southwest-northeast tilt of the North Atlantic storm track. The DJF response of the CMIP5 models can also primarily be interpreted as a change in the tilt of the storm track. This raises a number of questions concerning the sensitivity of the climate change response of North Atlantic cyclones to the historical biases in the CMIP5 models. Figure 3 shows the mean track density response computed for the CMIP5 models, which, as described in Zappa et al. (2013), have a better representation of the storm-track position and tilt: HadGEM2-ES, HadGEM2-CC, ${ }^{1}$ EC-EARTH, and MRI-CGCM3. Despite a better representation of the recent climate, which does not necessarily imply a more accurate projection, we note how the response of this subset of models is similar to the mean CMIP5 response. In particular, the tripolar pattern is still identified and the track density still increases over the United Kingdom and decreases in the Norwegian and Mediterranean Seas. Therefore, the broad features of the North Atlantic and European response appear to be weakly sensitive to the historical biases.

\section{c. Winter cyclone intensity response}

Figures $2 \mathrm{c}$ and $2 \mathrm{~d}$ show the change in the wind speeds associated with cyclones (dynamical intensity) for the RCP4.5 scenario. The CMIP5 models show a statistically significant reduction in the wind intensity of cyclones over the Mediterranean area the subtropical

\footnotetext{
${ }^{1}$ This model, not included in Zappa et al. (2013), has present-day cyclone statistics very similar to HadGEM2-ES. We include it here to reduce the sampling uncertainty on the mean response.
}

Atlantic, and the Norwegian Sea. A slight increase is found in northern France and Germany. Note that the mean responses in the wind intensity of cyclones (Fig. 2c) and in the track density (Fig. 2a) tend to be spatially coherent and have the same sign (e.g., both the number and the wind speed of cyclones decrease in the Mediterranean area and both show an increase close to the British Isles). Despite being significant, these signals have a small signal-to-noise ratio. Consensus in the model responses is generally found. These results are consistent with some single-model studies (Bengtsson et al. 2006; Pinto et al. 2007b).

Figures $2 \mathrm{e}$ and $2 \mathrm{f}$ show the future response in the mean precipitation associated with cyclones (hydrological intensity). The increase in precipitation is expected in response to the increased atmospheric moisture content in a warmer climate (Held and Soden 2006; Pall et al. 2007; Schneider et al. 2010). However, the response is not spatially uniform. The maximum increase occurs close to the eastern coast of the United States, which corresponds with the region of maximum precipitation in the HIST simulations. The response is instead small, and not significant, in the oceanic region to the southeast of Greenland. This pattern is consistent with the spatial distribution of the near-surface atmospheric warming (see Fig. 9a, described in greater detail below).

The response in the precipitation intensity is also small in the Mediterranean area. This may be a consequence of the reduction in the wind intensity of cyclones, which, by weakening the atmospheric vertical motions, tends to offset the thermodynamic tendency toward more precipitation (Emori and Brown 2005; Finnis et al. 2007). We cannot test the $f^{2}$ metric of consensus because, as discussed in section $2 \mathrm{c}$, the precipitation intensity is computed for a different number of years in the HIST (1975-2005) and RCP4.5 (2082-99) simulations and such asymmetry violates the constant variance assumption of the statistical framework. Multimodel consensus has been instead evaluated by simply considering whether at least $80 \%$ of the models agree on the sign of the response (not shown). Sign agreement in the precipitation response is generally found over all the regions featuring large precipitation increase (e.g., signal-to-noise ratio larger than 2), so this appears to be a robust feature of CMIP5 models.

In conclusion, there is emerging consensus in the response of North Atlantic and European cyclones in CMIP5 models. Rather than a poleward shift, the response is characterized by a tripolar pattern over Europe, with a reduction in cyclone activity (number and intensity) on the flanks of the storm track and in the Mediterranean, and an eastward extension toward the British Isles. To the north of $45^{\circ} \mathrm{N}$ and over the continents, 


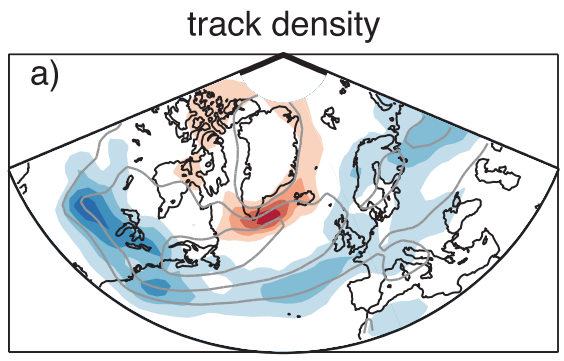

wind intensity

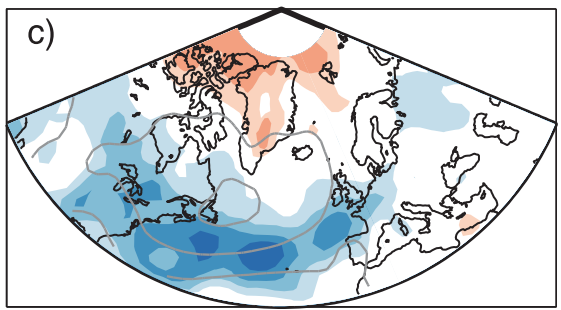

precip intensity

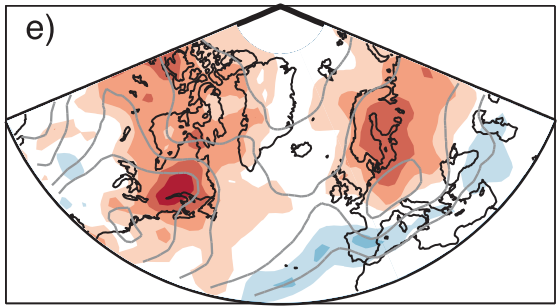

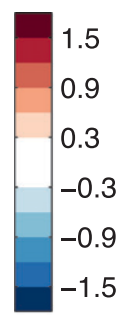
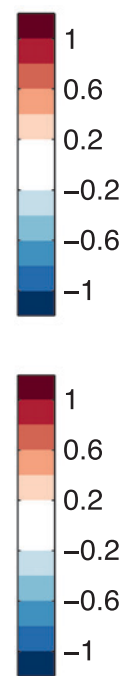

track density

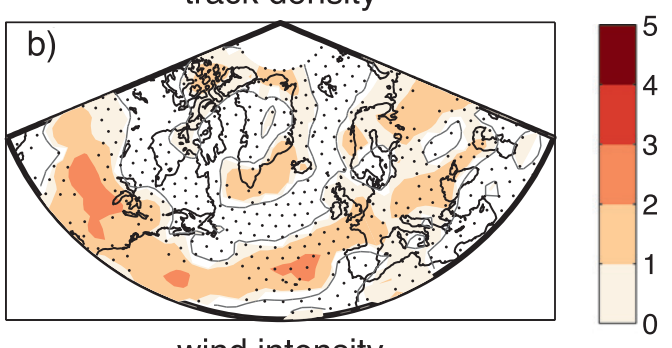

wind intensity

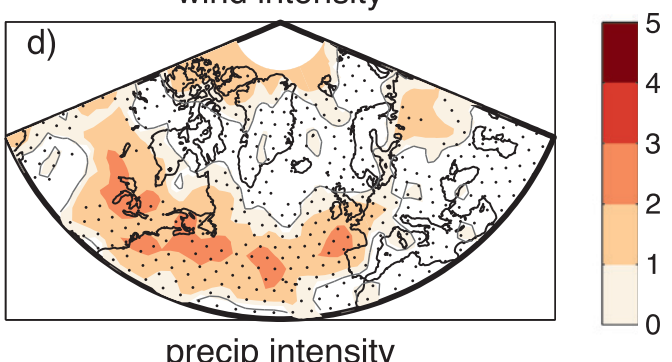

precip intensity
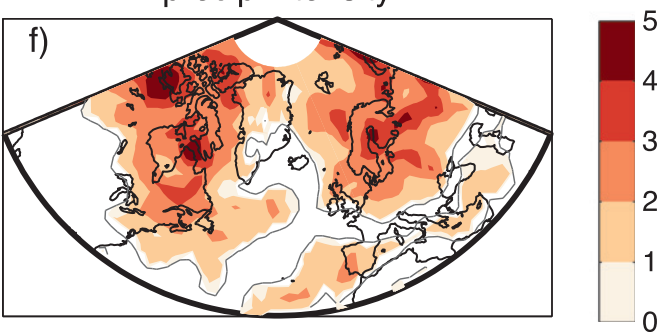

FIG. 4. As in Fig. 2, but for JJA.

the response of the largest signal-to-noise ratio is the increase in the mean precipitation intensity of cyclones. Instead, to the south of $45^{\circ} \mathrm{N}$, and especially in the Mediterranean area the track density reduction has the largest signal-to-noise ratio. The mean wind intensity of cyclones tends to decrease apart from over central Europe, where there is a small, but significant, increase.

\section{d. Summer track density response}

Figures $4 \mathrm{a}$ and $4 \mathrm{~b}$ show the JJA CMIP5 track density response to climate change for the RCP4.5 scenario. The mean response to climate change is a reduction in track density on the southern flank of the storm track $\left(35^{\circ}\right.$ $45^{\circ} \mathrm{N}$ ) and an increase in track density downstream of the southern tip of Greenland $\left(\sim 60^{\circ} \mathrm{N}\right)$. The pattern is consistent with the track density response found in single-model studies (Geng and Sugi 2003; Bengtsson et al. 2006) and also with the transient eddy kinetic energy response found by O'Gorman (2010) in the CMIP3 models. Such a meridional dipole might be suggestive of a poleward shift of the storm track, and, as discussed in section 5, a poleward shift is effectively found in the upper-tropospheric jet. However, at the surface, the reduction in the number of cyclones on the southern flank of the storm track seems to dominate. Also in JJA, as in $\mathrm{DJF}$, the signal-to-noise ratio of the responses is on the order of one.

There is consensus in the track density responses of CMIP5 models over most of the North Atlantic and Europe. No consensus is found in the reduction in track density over the United States and in the increase in track density close to Greenland. However, in North America the response has the same sign in the majority ( $>80 \%$ ) of CMIP5 models, which suggests that similar climate processes, but of different magnitudes, are occurring in the different models. This uncertainty does not appear to be related to the HIST track density biases in the region. No consensus in the sign of the response is also found in the track density increase close to Greenland. Differences in the representation of Greenland's orography and of its interaction with the response of the jet (see section 5) might contribute to such uncertainty.

\section{e. Summer cyclone intensity response}

Figures $4 \mathrm{c}$ and $4 \mathrm{~d}$ show that the mean dynamical intensity of cyclones decreases in JJA over the North Atlantic and North America, while no significant changes occur in the Norwegian Sea. In particular, the signal is 
largest along the southern flank of the storm track, in correspondence with the region where track density also tends to decrease. Consistent with the track density response, consensus in the model responses is again found over most of the domain with the exception of North America. The reduction in the mean wind intensity of cyclones in JJA tends to be larger compared with that found in DJF.

Figures $4 \mathrm{e}$ and $4 \mathrm{f}$ show that the precipitation intensity of cyclones is projected to increase, especially over land to the north of $50^{\circ} \mathrm{N}$. The response is instead weak in the subtropical central and eastern Atlantic, where the precipitation intensity even tends to decrease locally. As discussed for the Mediterranean area in DJF, this suggests that the reduction in the wind intensity of cyclones in the subtropical Atlantic acts against the precipitation increase expected from the increased atmospheric moisture content. The signals are still large compared with internal variability, especially over land and to the north of $50^{\circ} \mathrm{N}$.

In conclusion, the future response of North Atlantic cyclones in JJA is characterized by a reduction in cyclone activity (number and wind intensity) on the southern flank of the storm track $\left(30^{\circ}-45^{\circ} \mathrm{N}\right)$. At the same time, there is an increase in the precipitation intensity of cyclones especially over land and to the north of $50^{\circ} \mathrm{N}$. By comparing the signal-to-noise ratios, the increase in the precipitation of cyclones is the dominant signal emerging at high latitudes, while over a large midlatitude area $\left(30^{\circ}-45^{\circ} \mathrm{N}\right)$ the reduction in cyclone number and intensity have the largest signal-to-noise ratio. Cyclone intensity and number are also predicted to decrease over North America, but the size of the response is more uncertain.

\section{f. Sensitivity to scenario}

Figures $5 \mathrm{a}$ and $5 \mathrm{~b}$ show the DJF- and JJA-mean track density responses for the RCP8.5 scenario (RCP8.5 minus HIST). The patterns are very similar to those seen in the RCP4.5 scenario except that the magnitude of the $\mathrm{RCP} 8.5$ responses is roughly double those in the RCP4.5 scenario, consistent with increased anthropogenic forcing. The signal-to-noise ratio is also larger (not shown). For example, the track density reduction on the southern flank of the storm track reaches a signal-to-noise ratio of about 3 in both DJF and JJA.

Table 2 summarizes the sensitivity of the mean response to the emission scenario for different areas of interest. In particular, the mean response in the track density and in the wind speed and precipitation intensities area averaged over central Europe $\left(50^{\circ}-60^{\circ} \mathrm{N}\right.$, $\left.20^{\circ} \mathrm{W}-30^{\circ} \mathrm{E}\right)$ and the Mediterranean area $\left(30^{\circ}-45^{\circ} \mathrm{N}\right.$, $10^{\circ} \mathrm{W}-40^{\circ} \mathrm{E}$ ) are presented for the RCP 4.5 and RCP 8.5

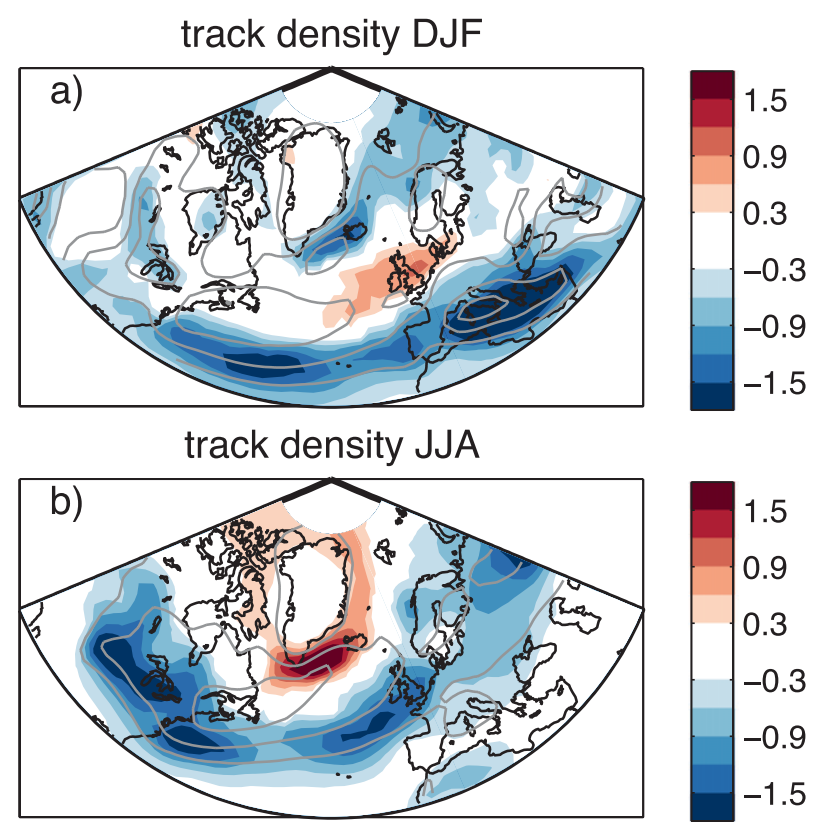

FIG. 5. As in Figs. 2a and 4a, but for the mean track density response to the RCP8.5 scenario in (a) DJF and (b) JJA. Units are in number of cyclones per month per unit area. Only the responses statistically significant at the $5 \%$ level are shown.

emission scenarios (these areas are also shown by boxes in Figs. 1a and 1b). The Mediterranean is only considered in DJF, when the regional storm track is more active. The $90 \%$ confidence intervals on the mean response caused by internal variability in the model runs are indicated in the table (see section $2 \mathrm{c}$ for more details).

For the RCP8.5 scenario, in the multimodel mean, a very large track density response is found in the Mediterranean in DJF $(-20 \% \pm 2 \%)$. For the same scenario, the track density decreases over central Europe in JJA $(-10 \% \pm 2 \%)$ but increases in DJF $(4 \% \pm$ $1 \%)$. The increase in the central European track density is also associated with an increase in the mean wind intensity of cyclones $(0.9 \% \pm 0.5 \%)$. A large increase in the precipitation intensity of cyclones is also found over central Europe in both DJF $(18 \% \pm 1 \%)$ and JJA $(9 \% \pm 1 \%)$. However, the spread of some of the model responses appears to be large, especially under the RCP8.5 scenario and for precipitation. For example, large responses of opposite signs are found for the European precipitation intensity in JJA $(-12 \%,+28 \%)$ and in the Mediterranean in DJF $(-14 \%,+9 \%)$. Such uncertainty is likely caused by the competing effects of increased moisture content and reduced cyclone intensity over these regions. Large spread is also found for the track density reduction over the Mediterranean in DJF $(-34 \%,-10 \%)$. 
TABLE 2. Area-averaged multimodel-mean response for the RCP4.5 and RCP8.5 emission scenarios in the central European area (EU; for DJF and JJA) and for the Mediterranean area (MED; for DJF). The investigated fields are the track density (Track den.), wind speed cyclone intensity (Wind), and precipitation cyclone intensity (Precip.). Here, $r(\%)$ is the mean response $\beta$ expressed as percentage change on the mean HIST values. The uncertainties show the $90 \%$ confidence intervals on $r$ caused by internal variability in the model runs (see section $2 \mathrm{c}$ for more details). Also, $\beta / \sigma$ is the signal-to-noise ratio.

\begin{tabular}{|c|c|c|c|c|c|c|c|}
\hline & \multirow[b]{2}{*}{ Scenario } & \multicolumn{2}{|c|}{ EU DJF } & \multicolumn{2}{|c|}{ EU JJA } & \multicolumn{2}{|c|}{ MED DJF } \\
\hline & & $r(\%)$ & $\beta / \sigma$ & $r(\%)$ & $\beta / \sigma$ & $r(\%)$ & $\beta / \sigma$ \\
\hline \multirow[t]{2}{*}{ Track den. } & RCP4.5 & $2 \pm 1$ & 0.7 & $-4 \pm 2$ & 1.2 & $-12 \pm 2$ & 2.9 \\
\hline & RCP8.5 & $4 \pm 1$ & 1.1 & $-10 \pm 2$ & 2.5 & $-20 \pm 2$ & 4.8 \\
\hline \multirow[t]{2}{*}{ Wind } & RCP4.5 & $0.4 \pm 0.5$ & 0.3 & $-1.4 \pm 0.5$ & 1.2 & $-1.8 \pm 0.5$ & 1.6 \\
\hline & RCP8.5 & $0.9 \pm 0.5$ & 0.8 & $-0.3 \pm 0.5$ & 0.2 & $-3.0 \pm 0.5$ & 2.5 \\
\hline \multirow{2}{*}{ Precip. } & RCP4.5 & $9 \pm 1$ & 7 & $8 \pm 1$ & 3.5 & $3 \pm 1$ & 1.5 \\
\hline & RCP8.5 & $18 \pm 1$ & 14 & $9 \pm 1$ & 3.8 & $0 \pm 1$ & 0.1 \\
\hline
\end{tabular}

\section{Response of strong cyclones}

We now describe the response of cyclones associated with strong wind speeds and precipitation. The response is presented using both basinwide statistics, to determine the changes in the overall characteristics of the storm track, and as a function of the location, which is more appropriate for interpreting the regional impacts.

\section{a. Basinwide response}

North Atlantic and European cyclones are defined as those reaching their maximum T42 vorticity at $850 \mathrm{hPa}$ (the tracked variable) within $30^{\circ}-90^{\circ} \mathrm{N}$ and $80^{\circ} \mathrm{W}-40^{\circ} \mathrm{E}$ (the area delimited in Figs. 1a,b). The frequency distribution (FD) of the maximum along-track wind intensity of North Atlantic and European cyclones, as measured by wind speed at $850 \mathrm{hPa}$, is then computed for each model. The multimodel means of the FD in the HIST and in the RCP4.5 simulations are shown in Figs. 6a and 6b. Little change is found between the two simulations. However, by looking at the difference (RCP4.5 minus HIST) in the FDs we find a reduction in the number of cyclones associated with $850-\mathrm{hPa}$ wind speed larger than $25 \mathrm{~m} \mathrm{~s}^{-1}$ in DJF and $20 \mathrm{~m} \mathrm{~s}^{-1}$ in JJA. This signal can also be seen in the tail of the FD, suggesting that the basinwide response is a reduction in the number of cyclones associated with strong $850-\mathrm{hPa}$ wind speeds.

To better compare the CMIP5 models, a metric of the number of strong cyclones is introduced that takes into account the HIST biases of the models. Strong cyclones are defined as those exceeding a threshold in the maximum along-track wind speed at $850 \mathrm{hPa}$. For each model and season, the threshold is chosen to be equal to the 90th percentile of the maximum along-track wind speed FD of North Atlantic and European cyclones in the HIST simulation. This allows us to always consider the strongest $10 \%$ of cyclones relative to the model climatology. In the multimodel mean, the number of strong
North Atlantic cyclones decreases by $-8 \% \pm 3 \%$ in DJF and by $-6 \% \pm 3 \%$ in JJA. Moreover, the total number of North Atlantic cyclones decreases by $-3.6 \% \pm 0.6 \%$ in $\mathrm{DJF}$ and $-1.9 \% \pm 0.6 \%$ in JJA.

Figures $7 \mathrm{a}$ and $7 \mathrm{~b}$ show the distribution of the CMIP5 model responses in the total number of cyclones, and in the number of cyclones associated with strong wind speeds, so that the spread of the responses can be investigated. The responses are shown for both the RCP4.5 and RCP8.5 scenarios. The total number of cyclones decreases in the majority of CMIP5 models in both the seasons and scenarios (i.e., the interquartile ranges lie entirely below zero). However, the spread of the model responses in JJA is roughly the double than in DJF, thus suggesting larger uncertainty in the summer. A similar picture is found for the response in the number of strong cyclones: a reduction is found in the majority of models in both DJF and JJA, but larger uncertainty characterizes JJA.

In summary, we have found that both the total number of North Atlantic cyclones and those of strong wind intensity tend to decrease in response to climate change. The sensitivity of the results to the adopted metric of cyclone dynamical intensity has been tested. We find that CMIP5 models also show a reduction in the number of North Atlantic cyclones associated with strong T42 vorticity at $850 \mathrm{hPa}$. When considering the along-track minimum in MSLP, the number of deep cyclones tends to decrease in DJF but a slight increase, with large spread, is found in JJA. This highlights that care is needed when using MSLP to evaluate changes in dynamical intensity under climate change. The minima in MSLP can be also affected by the variations in the largescale MSLP field (Bengtsson et al. 2009; Ulbrich et al. 2009). Moreover, as the radius of cyclones may also change (Schneidereit et al. 2010), deeper cyclones may not necessarily imply stronger winds, although larger cyclones may still have a higher impact on wave activity and storm surge. 

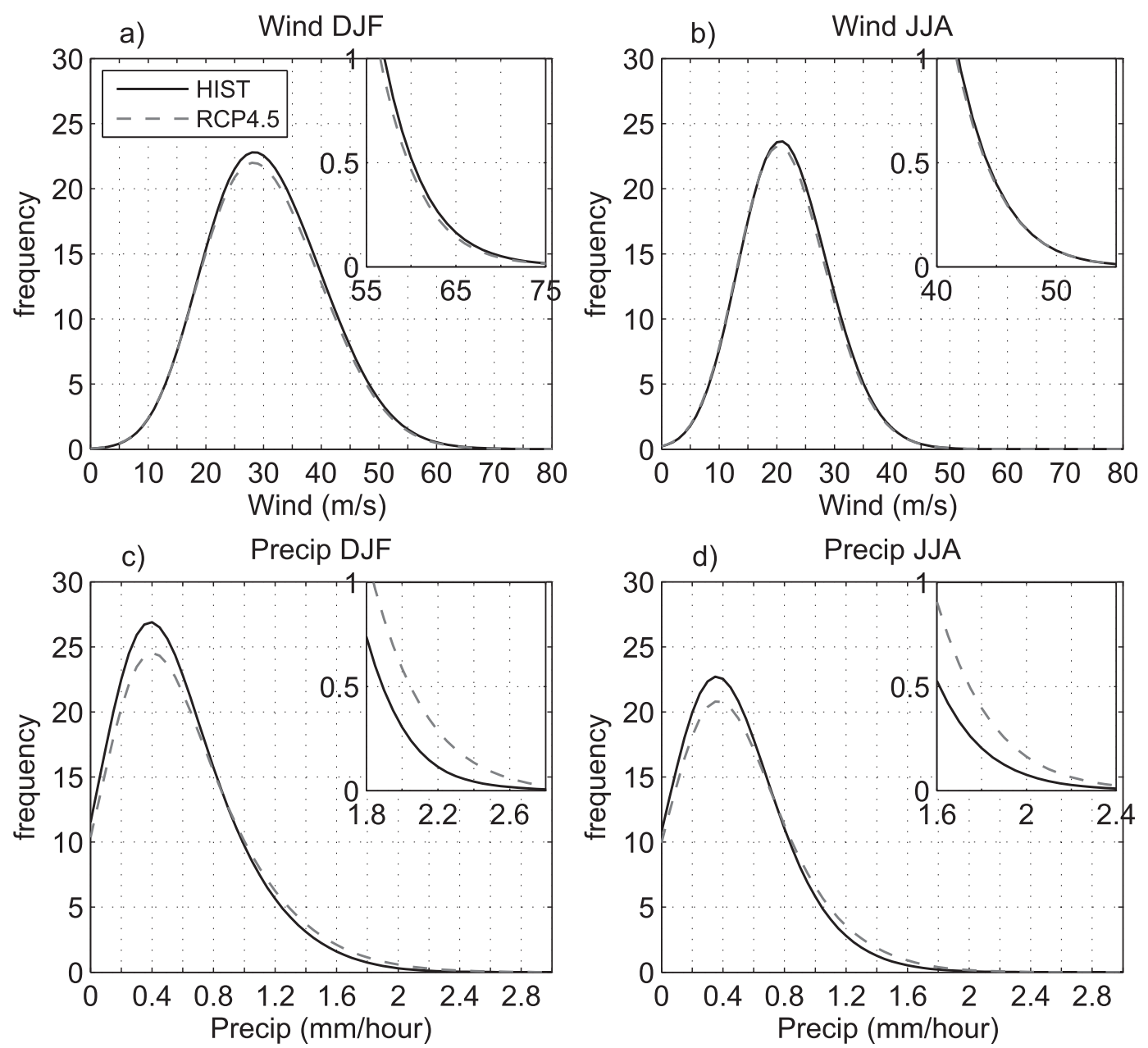

FIG. 6. Multimodel mean of the frequency distributions of the maximum (a),(b) along-track wind speed and (c),(d) precipitation of North Atlantic and European cyclones, for (left) DJF and (right) JJA. The full black line refers to the HIST simulation, and the dashed gray line to the RCP4.5 simulation. The frequency distribution of wind (precipitation) is scaled to the number of cyclones per season per $5 \mathrm{~m} \mathrm{~s}^{-1}\left(0.2 \mathrm{~mm} \mathrm{hr}^{-1}\right)$.

The same analysis presented for the wind intensity of cyclones has been repeated for the precipitation intensity (i.e., the area-averaged precipitation rate in a $5^{\circ}$ spherical cap centered on the cyclone). The FD of the along-track maxima in the cyclone precipitation intensity (Figs. 6c,d) shows a future reduction (RCP4.5 minus HIST) in the number of weakly precipitating cyclones and an increase in the number of strong and extreme precipitating cyclones in both DJF and JJA. In the multimodel mean, there is a $26 \% \pm 2 \%(\mathrm{DJF})$ and $33 \% \pm 2 \%(\mathrm{JJA})$ increase in the number of cyclones with precipitation intensity within the top $10 \%$ of the HIST simulations. Figure $7 \mathrm{c}$ shows that the response has the same sign in all the CMIP5 models, although the spread in the model responses appears to be large $(10 \%-56 \%$ in DJF and $0 \%-$ $60 \%$ in JJA). A larger mean signal and a larger spread of the responses are found for the RCP8.5 scenario.

\section{b. Spatial distribution of the strong cyclones' response}

Figure 8a shows the DJF-mean track density response of the subset of cyclones associated with strong wind speeds, which is defined in the previous subsection. Note that we here use stippling to identify areas with responses that are statistically significant at the $10 \%$ level. The DJF response is dominated by a large $(\sim 20 \%)$ track density reduction between Newfoundland and the Greenland Sea. This signal contributes to the basinwide reduction in the number of strong cyclones found in the previous subsection. However, we also note a smaller increase in the track density of strong cyclones between the British Isles and Scandinavia. In particular, the multimodel mean shows a track density increase of $3 \% \pm 5 \%$ by averaging the mean response over the same central European area considered in section $3 \mathrm{f}$. 

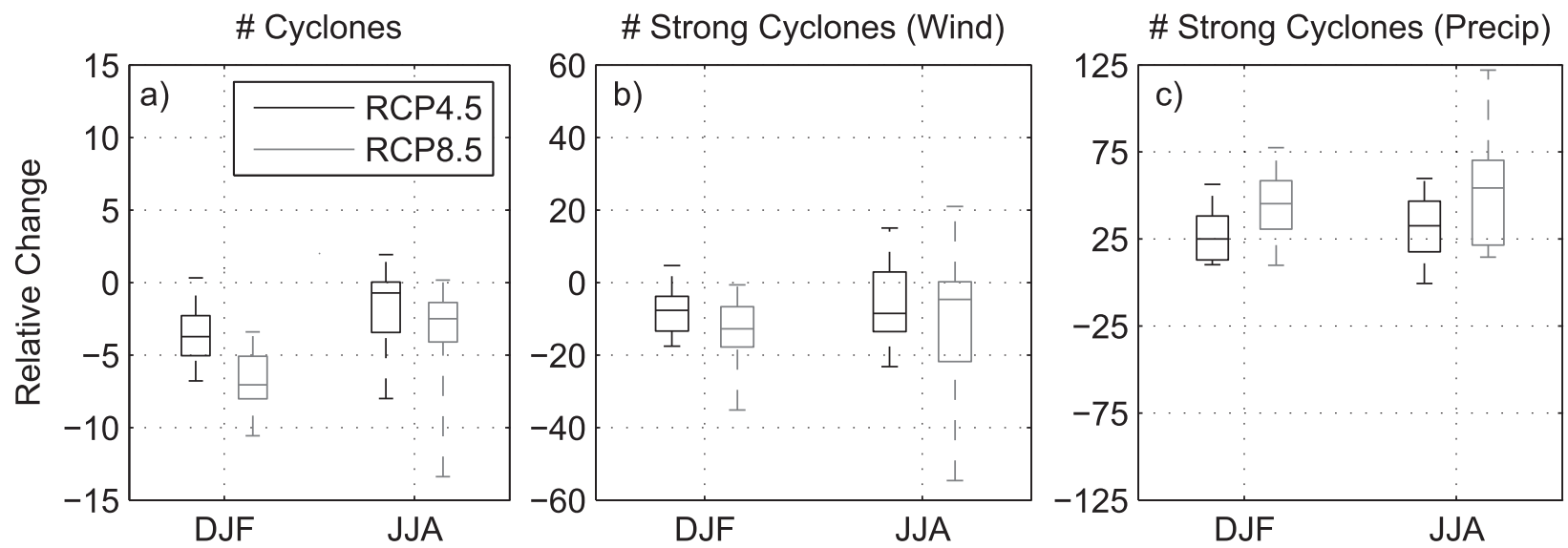

FIG. 7. Box plot of the distribution of the model responses in (a) the total number of cyclones, and the number of North Atlantic and European cyclones associated with (b) strong winds and (c) strong precipitation. The responses are expressed as changes relative to the HIST simulations. The center of the box is the median response, the edges of the box extend to the 25th-75th percentiles, and the whiskers extend to the minimum and maximum values. Strong cyclones are defined as in text.

To further analyze the increase in European storminess, Fig. $8 \mathrm{c}$ shows the mean response in the wind intensity of the subset of the strong cyclones. While no significant changes are found over most of the Atlantic, an increase in the 850-hPa wind speeds of the strong cyclones is found over central Europe in the multimodel mean $(3 \% \pm 1 \%)$. The increase in both the number and the wind intensity of the cyclones associated with strong wind speeds might contribute to larger economic loss potential from cyclone activity (Mailier et al. 2006; Pinto et al. 2012). However, the signal-to-noise ratio of the
European track density and intensity mean responses are small and CMIP5 models tend to agree that the responses are small compared with internal variability $\left(f^{2}<1\right)$.

Figures $8 \mathrm{~b}$ and $8 \mathrm{~d}$ show the same analysis but for JJA. The dominant track density signal is a reduction along the southern flank of the storm track and in particular over North America. However, the track density increases in the Norwegian Sea area. This dipolar structure is related to the larger uncertainty in the JJA response compared with DJF (see Fig. 7b). In some models the track density strong cyclones DJF

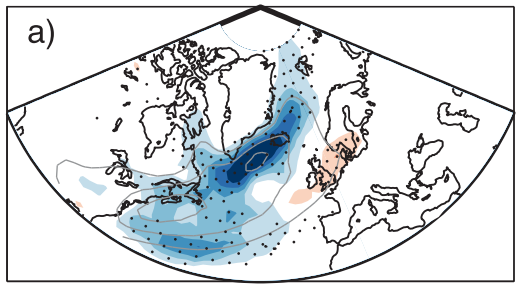

wind intensity strong cyclones DJF

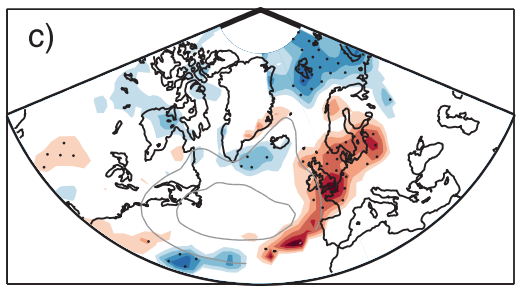

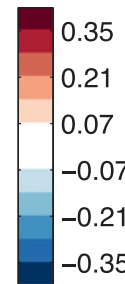

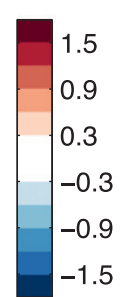

track density strong cyclones JJA

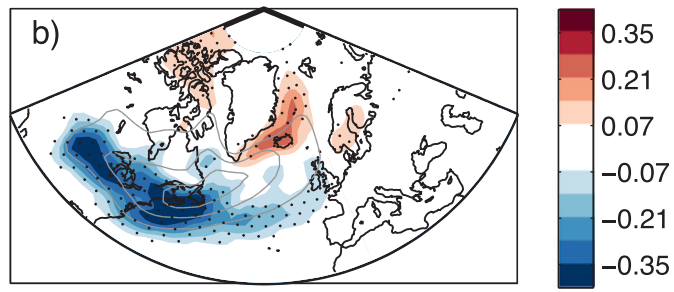

wind intensity strong cyclones JJA

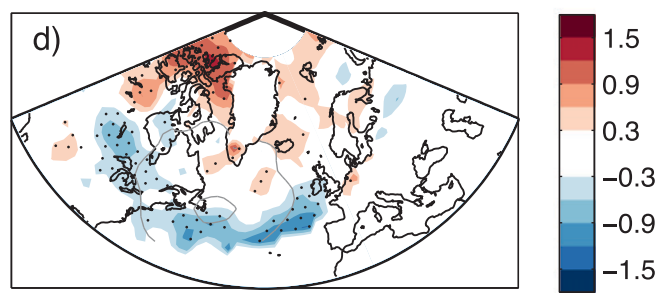

FIG. 8. Multimodel (a),(b) mean track density and (c),(d) wind speed intensity responses (RCP4.5 minus HIST) computed for the subset of strong cyclones, for (left) DJF and (right) JJA. Strong cyclones are defined as in text. Stippling is applied where the mean response is statistically significant at the $10 \%$ level. The contours show the multimodel-mean values in the HIST simulations. In (a) and (b), the CI is a cyclone per month per unit area. In (c) the displayed contours are 30 and $35 \mathrm{~m} \mathrm{~s}^{-1}$; in (d) they are 20 and $25 \mathrm{~m} \mathrm{~s}^{-1}$. In (c) and (d), the mean response is masked where the mean historical strong cyclones track density is smaller than 0.2 cyclones per month. 
Temp 2m DJF
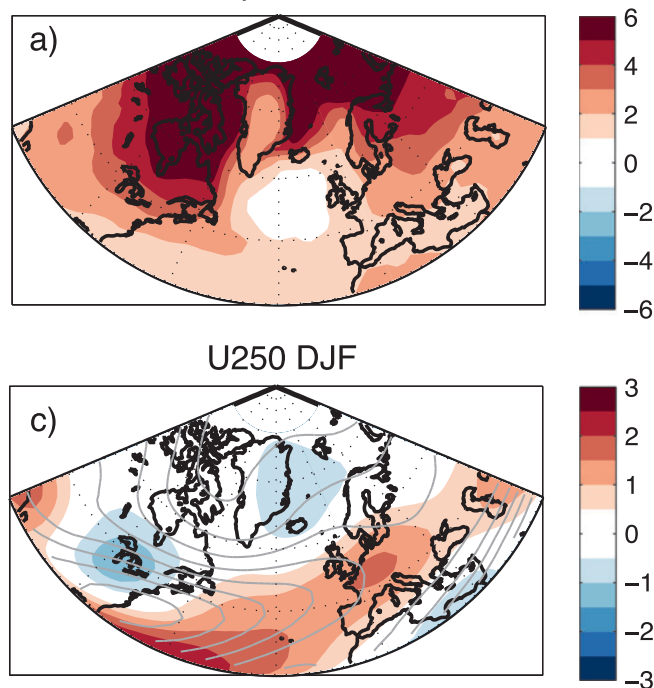

Temp 2m JJA
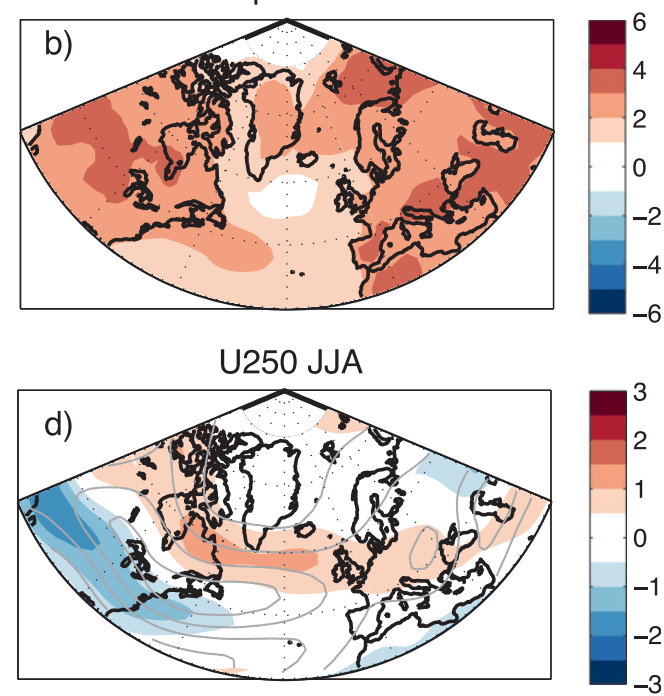

FIG. 9. Multimodel-mean response (RCP4.5 minus HIST) in the (a),(b) near-surface atmospheric air temperature $\left({ }^{\circ} \mathrm{C}\right)$ and (c),(d) zonal wind at $250 \mathrm{hPa}\left(\mathrm{m} \mathrm{s}^{-1}\right)$, for (left) DJF and (right) JJA. The mean values in the HIST simulations are contoured in (c) and (d) with a CI of $5 \mathrm{~m} \mathrm{~s}^{-1}$.

low-latitude reduction dominates (e.g., MIROC-ESM), while in other models the high-latitude increase dominates (e.g., MIROC5).

It is also of interest to note that the mean intensity of the strong cyclones generally shows no significant changes over most of the Atlantic in both DJF and JJA. This suggests that it is the number of strong cyclones, rather than their intensity, that is predominantly affected by the large-scale changes in the baroclinicity of the atmosphere. These changes are discussed in the next section.

\section{Relation to the large-scale environment}

The anthropogenic forcing will alter the state of the atmosphere, ocean, and sea ice. These changes may all affect the behavior of cyclones by modifying the baroclinicity of the atmosphere and the role of diabatic processes in cyclone development. Understanding the role of these physical drivers of change is important to gain confidence in climate model projections. However, care is needed when attributing the response in the behavior of cyclones to a specific change in a component of the climate system, as the responses of the different components are interconnected. Here, we investigate the consistency of the North Atlantic cyclone responses with the large-scale changes in the baroclinicity of the atmosphere. In particular, we discuss why the reduction in strong cyclone activity mainly occurs along the northern flank of the storm track in DJF and on the southern flank in JJA.
Figures $9 \mathrm{a}$ and $9 \mathrm{~b}$ show the mean climate response (RCP4.5 minus HIST) in the near-surface atmospheric air temperature $T_{2 \mathrm{~m}}$. The DJF response in $T_{2 \mathrm{~m}}$ is dominated by the surface polar amplification of global warming, which is related to the Arctic sea ice lost and radiative feedback processes (Holland and Bitz 2003). The low-level meridional temperature gradient and atmospheric baroclinicity along the northern flank of the storm track are therefore reduced. This is consistent with the found reduction in the number of strong cyclones. Furthermore, a minimum in SST warming is found in the North Atlantic. Previous studies suggested that this minimum in North Atlantic SST warming, which is associated with the weakening of the MOC, might strengthen the storm-track activity over the eastern Atlantic by enhancing the surface atmospheric baroclinicity (Brayshaw et al. 2009; Woollings et al. 2012). In JJA, the response in $T_{2 \mathrm{~m}}$ has a more uniform spatial distribution and it shows very little polar amplification of global warming. This is consistent with the absence of a decrease in high-latitude cyclone activity in JJA, in contrast to DJF.

Figures $9 \mathrm{c}$ and $9 \mathrm{~d}$ show the mean response (RCP4.5 minus HIST) in the zonal wind at $250 \mathrm{hPa} U_{250}$. The $U_{250}$ gives the intensity of the jet stream and is a measure of the atmospheric baroclinicity, via thermal wind balance. In DJF, the mean response of $U_{250}$ is composed of a strengthening on the subtropical side of the Atlantic jet stream and of an eastward extension into Europe. As suggested in previous single-model studies (e.g., Pinto et al. 2007b), the eastward extension of the jet appears to be consistent with the increase in European storminess. 
However, there is no clear picture of what basic climate process might drive such eastward extension. For instance, although the weakening of the MOC might in part play a role, an eastward extension of the jet is also found in slab ocean experiments where the oceanic heat transport is unchanged between present and future simulations (Woollings et al. 2012). Future analyses will have to understand this important aspect of the regional atmospheric circulation change. An apparent inconsistency between the jet and the tracks is found in the subtropical central Atlantic where the jet becomes stronger but the number of cyclones decreases. Also, Mizuta (2012) finds little association in the month-tomonth variability between the observed jet stream speed and the number of strong cyclones over this region. This may suggest that the enhanced baroclinicity associated with the stronger subtropical jet is not available for cyclone development, possibly because it is too far south from the region of highest low-level baroclinicity that sits over the Gulf Stream. Other mechanisms, discussed below, might therefore be important in this region.

In JJA, the response in the jet stream appears to be well associated with the response in the cyclone tracks. The $U_{250}$ decreases on the southern flank of the jet stream and increases on the northern flank (see Fig. 9d). The pattern is suggestive of a poleward shift and resembles the track density response. A common feature of the DJF and JJA track density and wind intensity responses is therefore a reduction on the southernmost latitudes with cyclone activity, including the previously discussed subtropical central Atlantic area, which has a strengthened jet stream in DJF. This common feature is likely associated with the well-known tendency to a broadening of the tropics and increase in subtropical static stability in response to climate change (Seidel et al. 2007; Lu et al. 2008, 2009).

\section{Conclusions and discussion}

In this study, we have investigated the response of the winter (DJF) and summer (JJA) North Atlantic and European extratropical cyclones to climate change in the CMIP5 models. This is motivated by the large socioeconomic impacts that changes in the location and intensity of extratropical cyclones might have on Europe. The climate response is computed as a difference between 30-yr periods of the historical (HIST; 1976-2005) and future day (2070-99) simulations in the RCP4.5 and RCP8.5 emission scenarios. A cyclone-tracking technique (Hodges 1994, 1999) is used to quantify the response in the number of cyclones and in their intensity, which is measured by the maximum wind speed at $850 \mathrm{hPa}$ (dynamical intensity) and by the area-averaged precipitation (hydrological intensity). In contrast to previous studies that only looked at cyclone tracks in individual or small groups of models, the inspection of a large multimodel ensemble allows the uncertainties in the projection to be quantified (Sansom et al. 2013).

With regard to the response in the RCP4.5 scenario, the main results of this study are as follows:

- In DJF, the response of North Atlantic and European cyclones is characterized by a tripolar pattern, rather than by a poleward shift. In the multimodel mean, the number of cyclones decreases in the Norwegian Sea, while a small, but significant, increase is found over the British Isles $(3 \% \pm 2 \%)$. Here, all the presented uncertainties are $90 \%$ confidence intervals in the mean response caused by internal variability in the model runs, and not the spread in the model responses. A larger reduction in the number of cyclones is found in the Mediterranean Sea $(-12 \% \pm 2 \%)$. The total number of cyclones decreases $(-3.6 \% \pm 0.6 \%)$.

- In JJA, there is a reduction in cyclone activity (number and intensity) along the southern flank of the North Atlantic storm track, which is associated with the poleward shift of the upper-tropospheric jet. The total number of cyclones decreases $(-1.9 \% \pm 0.6 \%)$.

- The mean precipitation intensity of cyclones shows a large increase consistent with the warming of surface air temperature. To the north of $45^{\circ} \mathrm{N}$, and especially over land, the signal-to-noise ratio is in the range 4-6, which is large compared with the response in the number and wind intensity of cyclones.

- On a basin scale, the number of cyclones associated with the $90 \%$ percentile strong wind speed decreases. However, both the number $(3 \% \pm 5 \%)$ and the mean wind speed $(3 \% \pm 1 \%)$ of these strong cyclones increase over the United Kingdom and central Europe in DJF.

- The spread in the response of the models varies depending on the variable and the region of interest. Larger spread is generally found for the precipitation intensity, and the track density over the Mediterranean Sea in DJF and over North America in JJA. Good consensus is instead found in the track density and wind intensity responses over Europe in DJF.

- Apart from the larger Mediterranean response in DJF, the track density and wind intensity responses have a signal-to-noise ratio on the order of one. This clearly indicates that using multiple runs of the present and future climate is needed to accurately quantify the response of extratropical cyclones in climate model simulations.

The same conclusions are drawn from the climate response to the RCP8.5 scenario, where both the mean 
response and the spread of the model responses tend to become larger.

There are multiple factors that contribute to the confidence in these multimodel projections. First, the results seem qualitatively consistent with the findings of two other recent analyses of extratropical cyclones in the CMIP5 models (Chang et al. 2012; Mizuta 2012), which use different tracking algorithms. The similarity suggests that the projections presented here are likely to be robust with respect to the employed methodology. Second, under the RCP4.5 forcing, we have found that the uncertainty in the track density and wind intensity projections caused by differences in the responses of the models tend to be smaller than the uncertainty caused by internal variability. This is indicative of consensus among the CMIP5 model projections. Moreover, the mean response of the CMIP5 models also appears to be similar to those given in previous single model studies (Sinclair and Watterson 1999; Geng and Sugi 2003; Leckebusch and Ulbrich 2004; Pinto et al. 2007b; Bengtsson et al. 2006, 2009; Pinto et al. 2009; Catto et al. 2011), some of which also used a different tracking algorithm. Third, the tripolar pattern characterizing the response of North Atlantic cyclones in DJF seems to be only weakly affected by the biases of the models in capturing the observed tilt and the position of the North Atlantic storm track. Finally, the response of the cyclones appears to be consistent with well-known changes in the large-scale environment such as the broadening of the tropics, the polar amplification of global warming (DJF), and the North Atlantic jet stream poleward shift (JJA) and eastward extension into Europe (DJF).

The ultimate source of confidence comes from detecting and attributing the changes predicted by the models in the observed cyclone statistics. This study identifies the responses that can be expected to emerge first from internal variability. The increase in the mid- to highlatitude precipitation intensity of cyclones over land has the largest signal-to-noise ratio, followed by the reduction in the number of Mediterranean cyclones in DJF and by the reduction in cyclone activity along the southern flank of the Atlantic storm track in JJA. The signal-to-noise ratio in the responses of the number and wind intensity of North Atlantic cyclones in DJF appear to be small, which might make the detection of any change more difficult.

These results suggest that changes in North Atlantic and European cyclones may be important for adaptation planning to climate change. In particular, the increase in both the precipitation and wind intensity of cyclones can enhance the flood and windstorm risk over the British Isles and central Europe. The large reduction in the number of Mediterranean cyclones in winter may affect the freshwater availability of the region, which is largely dependent on the storage of the cyclone-generated wintertime precipitation. To increase confidence in these projections, it would be useful to better understand their relation with the physical drivers of change. In particular, the sensitivity of cyclone behavior to the tropical SST warming, the North Atlantic SST warming, the weakening of the MOC, and the Arctic sea ice loss will be investigated in future research.

Acknowledgments. We thank three anonymous reviewers for their constructive comments. We also acknowledge the World Climate Research Programme's Working Group on Coupled Modelling, which is responsible for CMIP, and we thank the climate modeling groups (listed in Table 1) for producing and making available their model output. For CMIP, the U.S. Department of Energy's Program for Climate Model Diagnosis and Intercomparison provides coordinating support and led development of software infrastructure in partnership with the Global Organization for Earth System Science Portals. This research has been done under the Testing and Evaluating Model Projections of European Storms (TEMPEST) project, which is founded by the Natural and Environmental Research Council. GZ would like to thank R. Lee for the help in retrieving some of the CMIP5 data.

\section{APPENDIX}

\section{Statistical Framework}

\section{a. The ANOVA framework}

Let $y_{m s r}$ represent a climate statistic from model $m$, scenario $s$, and run $r$ from a multimodel ensemble of $M$ models and $N$ runs containing a historical $H$ and a future $F$ scenario. Sansom et al. (2013) show that $y_{m s r}$ can be described by the ANOVA framework:

$$
\begin{aligned}
& y_{m s r}=\mu+\alpha_{m}+\beta_{s}+\gamma_{m s}+\epsilon_{m s r} \quad \text { and } \\
& \epsilon_{m s r} \stackrel{i i d}{\sim} N\left(0, \sigma^{2}\right),
\end{aligned}
$$

where the effect $\mu$ is the expected climate in the historical scenario and $\beta_{F}$ is the expected climate change response. The effect $\alpha_{m}$ is the difference between the historical climate of model $m$ and the expected climate $\mu$. The interaction terms $\gamma_{m F}$ represent the difference between the climate response simulated by model $m$ and the expected response $\beta_{F}$. The random component $\epsilon_{m s r}$ represents the internal variability in the $y_{m s r}$ and is assumed to be normally distributed. The framework is subject to the constraints that $\sum_{m=1}^{M} \alpha_{m}=0, \beta_{H}=0$, and $\gamma_{m H}=0$ for all models and $\sum_{m=1}^{M} \gamma_{m F}=0$. 


\section{b. Mean climate response}

The ML estimate $\hat{\beta}_{F}$ of the expected climate response $\beta_{F}$ is

$$
\hat{\beta}_{F}=\frac{1}{M} \sum_{m=1}^{M}\left(\bar{y}_{m F}-\bar{y}_{m H .}\right),
$$

where $R_{m s}$ is the number of runs of model $m$ in scenario $s$ and $\bar{y}_{m s .}$ is the average of $y_{m s r}$ over the multiple runs. Note that $\hat{\beta}_{F}$ is equivalent to the "one model, one vote" multimodel-mean approach of the climate response estimate.

The estimated variance of $\beta_{F}$ is

$$
\begin{aligned}
\operatorname{Var}\left(\hat{\beta}_{F}\right) & =\frac{\hat{\sigma}^{2}}{M^{2}} \sum_{m=1}^{M}\left(\frac{R_{m H}+R_{m F}}{R_{m H} R_{m F}}\right) \text { and } \\
\hat{\sigma}^{2} & =\frac{1}{N-2 M} \sum_{m=1}^{M} \sum_{s \in(H, F)} \sum_{r=1}^{R_{m s}}\left(y_{m s r}-\bar{y}_{m s .}\right)^{2},
\end{aligned}
$$

where $\hat{\sigma}^{2}$ is the ML estimate of the internal variability. The signal-to-noise ratio is defined as $\hat{\beta}_{F} / \hat{\sigma}$. Only for the precipitation intensity, because of data limitations, $\sigma$ is computed exclusively from the HIST runs. See Sansom et al. (2013) for full details of the estimation procedure.

The hypothesis of a nonzero climate response $\left(H_{a}\right.$; $\left.\beta_{F} \neq 0\right)$ can be tested by comparing the test statistic

$$
T_{\beta}=\frac{\left|\hat{\beta}_{F}-0\right|}{\sqrt{\operatorname{Var}\left(\hat{\beta}_{F}\right)}},
$$

with the quantiles of the $t$ distribution with $N-2 M$ degrees of freedom.

The relative amplitude of the mean climate response $r=\hat{\beta}_{F} / \hat{\mu}$ has variance $\operatorname{Var}(r) \sim \operatorname{Var}\left(\hat{\beta}_{F}\right) / \hat{\mu}$, where $\hat{\mu}$ is the multimodel-mean historical climate. The uncertainty in $\mu$ has been neglected as small relative to that in $\hat{\beta}_{F}$.

\section{c. Variance ratio $f^{2}$}

The variance ratio $f^{2}$ is a useful measure of agreement between models on the climate change response. It is the ratio of the variance explained by the model dependence in the climate change response $\left(\gamma_{m F}\right.$ interaction terms) relative to the variance explained by the internal variability. The fraction of variance explained by internal variability is given by $1-R_{\gamma}^{2}$, where $R_{\gamma}^{2}$ is the coefficient of determination of the ANOVA framework. The coefficient of determination gives the proportion of the total variability explained by the framework. The fraction of variance explained by the model-dependent component is obtained as the difference between the variance explained by the ANOVA framework above $R_{\gamma}^{2}$ and the variance explained by a simpler framework $R_{\alpha}^{2}$, where the interaction terms are constrained to be zero $\left(\gamma_{m F}=0 \forall m\right)$. Therefore, $f^{2}=\left(R_{\gamma}^{2}-R_{\alpha}^{2}\right) /\left(1-R_{\gamma}^{2}\right)$. See Sansom et al. (2013) for a detailed description of the simpler framework.

\section{REFERENCES}

Bengtsson, L., K. I. Hodges, and E. Roeckner, 2006: Storm tracks and climate change. J. Climate, 19, 3518-3543.

- , — , and N. Keenlyside, 2009: Will extratropical storms intensify in a warmer climate? J. Climate, 22, 2276-2301.

Blender, R., and M. Schubert, 2000: Cyclone tracking in different spatial and temporal resolutions. Mon. Wea. Rev., 128, $377-$ 384.

Brayshaw, D. J., T. Woollings, and M. Vellinga, 2009: Tropical and extratropical responses of the North Atlantic atmospheric circulation to a sustained weakening of the MOC. J. Climate, 22, 3146-3155.

Catto, J., L. Shaffrey, and K. Hodges, 2011: Northern Hemisphere extratropical cyclones in a warming climate in the HiGEM high-resolution climate model. J. Climate, 24, 5336-5352.

Chang, E. K. M., Y. Guo, and X. Xia, 2012: CMIP5 multi-model ensemble projection of storm track change under global warming. J. Geophys. Res., 117, D23118, doi:10.1029/2012JD018578.

Della-Marta, P. M., and J. G. Pinto, 2009: Statistical uncertainty of changes in winter storms over the North Atlantic and Europe in an ensemble of transient climate simulations. Geophys. Res. Lett., 36, L14703, doi:10.1029/2009GL038557.

Emori, S., and S. J. Brown, 2005: Dynamic and thermodynamic changes in mean and extreme precipitation under changed climate. Geophys. Res. Lett., 32, L17706, doi:10.1029/2005GL023272.

Fink, A., T. Brücher, V. Ermert, A. Krüger, and J. G. Pinto, 2009: The European storm Kyrill in January 2007: Synoptic evolution, meteorological impacts and some considerations with respect to climate change. Nat. Hazards Earth Syst. Sci., 9, 405-423.

Finnis, J., M. Holland, M. Serreze, and J. Cassano, 2007: Response of Northern Hemisphere extratropical cyclone activity and associated precipitation to climate change, as represented by the Community Climate System Model. J. Geophys. Res., 112, G04S42, doi:10.1029/2006JG000286.

Fu, Q., C. M. Johanson, J. M. Wallace, and T. Reichler, 2006: Enhanced mid-latitude tropospheric warming in satellite measurements. Science, 312, 1179-1179.

Geng, Q., and M. Sugi, 2003: Possible change of extratropical cyclone activity due to enhanced greenhouse gases and sulfate aerosols-Study with a high-resolution AGCM. J. Climate, 16, 2262-2274.

Harvey, B. J., L. C. Shaffrey, T. J. Woollings, G. Zappa, and K. I. Hodges, 2012: How large are projected 21st century storm track changes? Geophys. Res. Lett., 39, L18707, doi:10.1029/ 2012GL052873.

Hawcroft, M. K., L. C. Shaffrey, and H. F. Dacre, 2012: How much Northern Hemisphere precipitation is associated with extratropical cyclones? Geophys. Res. Lett., 39, L24809, doi:10.1029/ 2012GL053866.

Held, I., 1993: Large-scale dynamics and global warming. Bull. Amer. Meteor. Soc., 74, 228-241.

, and B. Soden, 2006: Robust responses of the hydrological cycle to global warming. J. Climate, 19, 5686-5699. 
Hodges, K. I., 1994: A general method for tracking analysis and its application to meteorological data. Mon. Wea. Rev., 122, 2573 2586.

_, 1995: Feature tracking on the unit sphere. Mon. Wea. Rev., 123, 3458-3465.

, 1996: Spherical nonparametric estimators applied to the UGAMP model integration for AMIP. Mon. Wea. Rev., 124, 2914-2932.

_ 1999: Adaptive constraints for feature tracking. Mon. Wea. Rev., 127, 1362-1373.

Holland, M. M., and C. M. Bitz, 2003: Polar amplification of climate change in coupled models. Climate Dyn., 21, 221-232.

Hoskins, B., and P. Valdes, 1990: On the existence of storm-tracks. J. Atmos. Sci., 47, 1854-1864.

Hwang, Y., D. Frierson, and J. Kay, 2011: Coupling between Arctic feedbacks and changes in poleward energy transport. Geophys. Res. Lett., 38, L17704, doi:10.1029/2011GL048546.

Laîné, A., M. Kageyama, D. Salas-Mélia, G. Ramstein, S. Planton, S. Denvil, and S. Tyteca, 2009: An energetics study of wintertime Northern Hemisphere storm tracks under $4 \times \mathrm{CO}_{2}$ conditions in two ocean-atmosphere coupled models. J. Climate, 22, 819-839.

Lamb, H., 1991: Historic Storms of the North Sea, British Isles and Northwest Europe. Cambridge University Press, 204 pp.

Lambert, S. J., and J. C. Fyfe, 2006: Changes in winter cyclone frequencies and strengths simulated in enhanced greenhouse warming experiments: Results from the models participating in the IPCC diagnostic exercise. Climate Dyn., 26, 713-728.

Leckebusch, G. C., and U. Ulbrich, 2004: On the relationship between cyclones and extreme windstorm events over Europe under climate change. Global Planet. Change, 44, 181-193.

Lionello, P., and F. Giorgi, 2007: Winter precipitation and cyclones in the Mediterranean region: Future climate scenarios in a regional simulation. Adv. Geosci., 12, 153-158.

Lu, J., G. Chen, and D. M. W. Frierson, 2008: Response of the zonal mean atmospheric circulation to El Niño versus global warming. J. Climate, 21, 5835-5851.

,- C. Deser, and T. Reichler, 2009: Cause of the widening of the tropical belt since 1958. Geophys. Res. Lett., 36, L03803, doi:10.1029/2008GL036076.

Mailier, P., D. Stephenson, C. Ferro, and K. I. Hodges, 2006: Serial clustering of extratropical cyclones. Mon. Wea. Rev., 134, 2224-2240.

Meehl, G., and Coauthors, 2007: Global climate projections. Climate Change 2007: The Physical Science Basis, S. Solomon et al., Eds., Cambridge University Press, 747-845.

Meinshausen, M., and Coauthors, 2011: The RCP greenhouse gas concentrations and their extensions from 1765 to 2300 . Climatic Change, 109, 213-241, doi:10.1007/s10584-011-0156-z.

Mizuta, R., 2012: Intensification of extratropical cyclones associated with the polar jet change in the CMIP5 global warming projections. Geophys. Res. Lett., 39, L19707, doi:10.1029/ 2012GL053032.

Neu, U., and Coauthors, 2013: IMILAST-A community effort to intercompare extratropical cyclone detection and tracking algorithms. Bull. Amer. Meteor. Soc., 94, 529-547.

O'Gorman, P. A., 2010: Understanding the varied response of the extratropical storm tracks to climate change. Proc. Natl. Acad. Sci. USA, 107, 19176-19180.

Pall, P., M. R. Allen, and D. A. Stone, 2007: Testing the ClausiusClapeyron constraint on changes in extreme precipitation under $\mathrm{CO}_{2}$ warming. Climate Dyn., 28, 351-363.
Pinto, J. G., E. Fröhlich, G. Leckebusch, and U. Ulbrich, 2007a: Changing European storm loss potentials under modified climate conditions according to ensemble simulations of the ECHAM5/MPI-OM1 GCM. Nat. Hazards Earth Syst. Sci., 7, $165-175$.

, U. Ulbrich, G. Leckebusch, T. Spangehl, M. Reyers, and S. Zacharias, 2007b: Changes in storm track and cyclone activity in three SRES ensemble experiments with the ECHAM5/ MPI-OM1 GCM. Climate Dyn., 29, 195-210.

—, T. Spangehl, A. Fink, G. C. Leckebusch, and U. Ulbrich, 2009: Factors contributing to the development of extreme North Atlantic cyclones and their relationship with the NAO. Climate Dyn., 32, 711-737.

_, M. K. Karremann, K. Born, P. M. Della-Marta, and M. Klawa, 2012: Loss potentials associated with European windstorms under future climate conditions. Climate Res., 54, 1-20.

Raible, C. C., B. Ziv, H. Saaroni, and M. Wild, 2010: Winter synoptic-scale variability over the Mediterranean Basin under future climate conditions as simulated by the ECHAM5. Climate Dyn., 35, 473-488.

Sansom, P. G., D. Stephenson, C. Ferro, G. Zappa, and L. Shaffrey, 2013: Simple uncertainty frameworks for selecting weighting schemes and interpreting multimodel ensemble climate change experiments. J. Climate, 26, 4017-4037.

Schneider, T., P. O'Gorman, and X. Levin, 2010: Water vapor and the dynamics of climate changes. Rev. Geophys., 48, RG3001, doi:10.1029/2009RG000302.

Schneidereit, A., R. Blender, and K. Fraedrich, 2010: A radiusdepth model for midlatitude cyclones in reanalysis data and simulations. Quart. J. Roy. Meteor. Soc., 136, 50-60.

Schubert, M., J. Perlwitz, R. Blender, K. Fraedrich, and F. Lunkeit, 1998: North Atlantic cyclones in $\mathrm{CO}_{2}$-induced warm climate simulations: Frequency, intensity, and tracks. Climate Dyn., 14, 827-837.

Seidel, D. J., Q. Fu, W. J. Randel, and T. J. Reichler, 2007: Widening of the tropical belt in a changing climate. Nat. Geosci., 1, 21-24.

Sinclair, M., and I. Watterson, 1999: Objective assessment of extratropical weather systems in simulated climates. J. Climate, 12, 3467-3485.

Taylor, K., R. Stouffer, and G. Meehl, 2012: An overview of CMIP5 and the experiment design. Bull. Amer. Meteor. Soc., 93, 485498.

Ulbrich, U., J. G. Pinto, H. Kupfer, G. C. Leckebusch, T. Spangehl, and M. Reyers, 2008: Changing Northern Hemisphere storm tracks in an ensemble of IPCC climate change simulations. J. Climate, 21, 1669-1679.

— G. Geckebusch, and J. Pinto, 2009: Extra-tropical cyclones in the present and future climate: A review. Theor. Appl. Climatol., 96, 117-131.

Woollings, T., 2010: Dynamical influences on European climate: An uncertain future. Philos. Trans. Roy. Soc., 368A, 3733 3756.

— J. M. Gregory, J. G. Pinto, M. Reyers, and D. J. Brayshaw, 2012: Response of the North Atlantic storm track to climate change shaped by ocean-atmosphere coupling. Nat. Geosci., $\mathbf{5}$, 313-317.

Yin, J., 2005: A consistent poleward shift of the storm tracks in simulations of 21st century climate. Geophys. Res. Lett., 32, L18701, doi:10.1029/2005GL023684.

Zappa, G., L. Shaffrey, and K. Hodges, 2013: The ability of CMIP5 models to simulate North Atlantic extratropical cyclones. J. Climate, 26, 5379-5396. 